Supplement of Hydrol. Earth Syst. Sci., 23, 1113-1144, 2019

https://doi.org/10.5194/hess-23-1113-2019-supplement

(c) Author(s) 2019. This work is distributed under

the Creative Commons Attribution 4.0 License.

(c) (1)

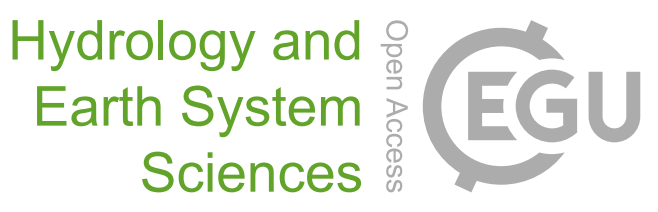

Supplement of

\title{
Multi-site calibration and validation of SWAT with satellite-based evapotranspiration in a data-sparse catchment in southwestern Nigeria
}

\author{
Abolanle E. Odusanya et al. \\ Correspondence to: Bano Mehdi (bano.mehdi@ boku.ac.at)
}

The copyright of individual parts of the supplement might differ from the CC BY 4.0 License. 

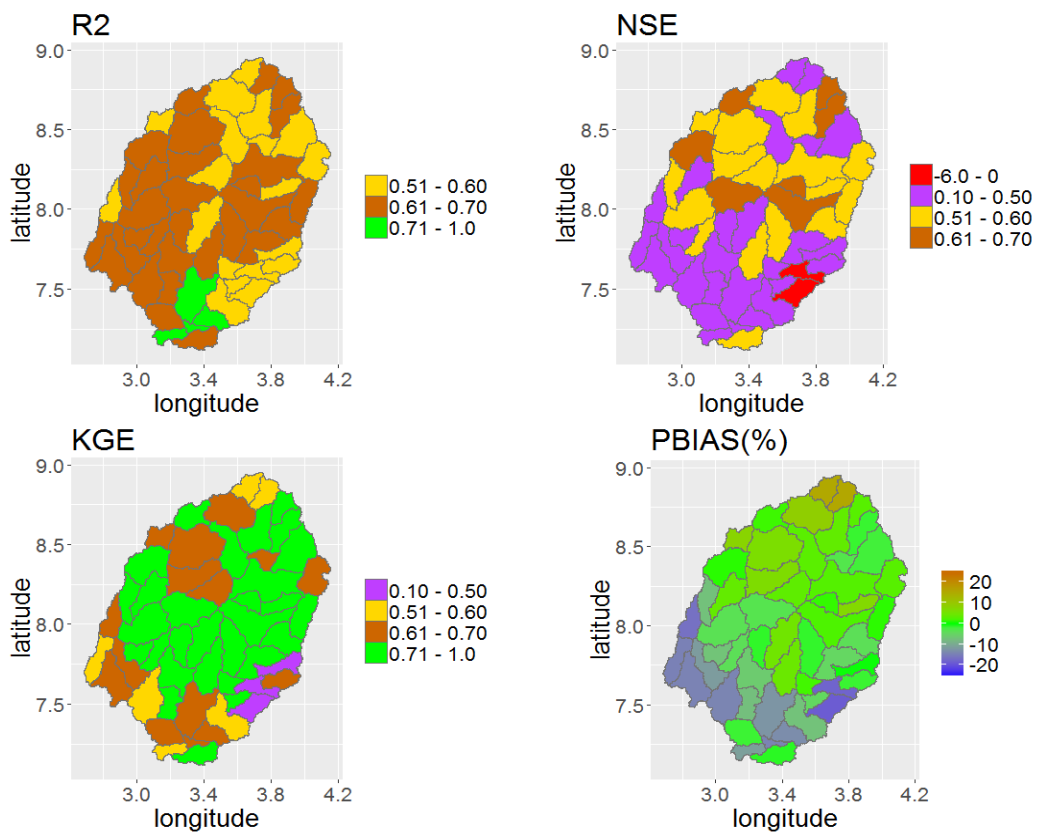

Figure S1: Performance metrics (NSE, KGE, $\mathbf{R}^{2}$, and PBIAS) of SWAT (SWAT_P-T) when calibrated with GLEAM_v3.0a (GS2).
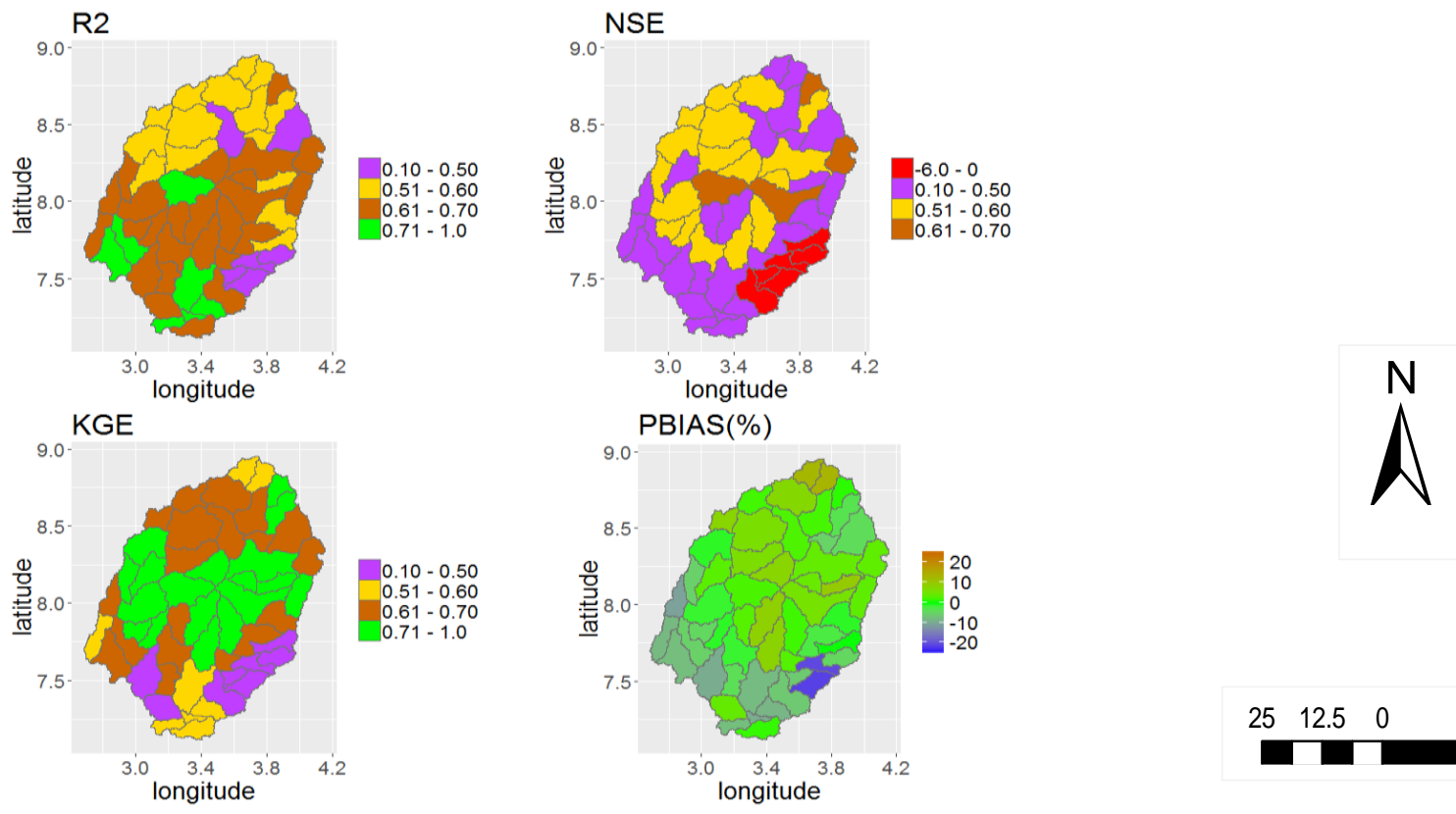

Figure S2: Performance metrics (NSE, KGE, ${ }^{2}$, and PBIAS) of SWAT (SWAT_P-T) when validated with GLEAM_v3.0a (GS2). 

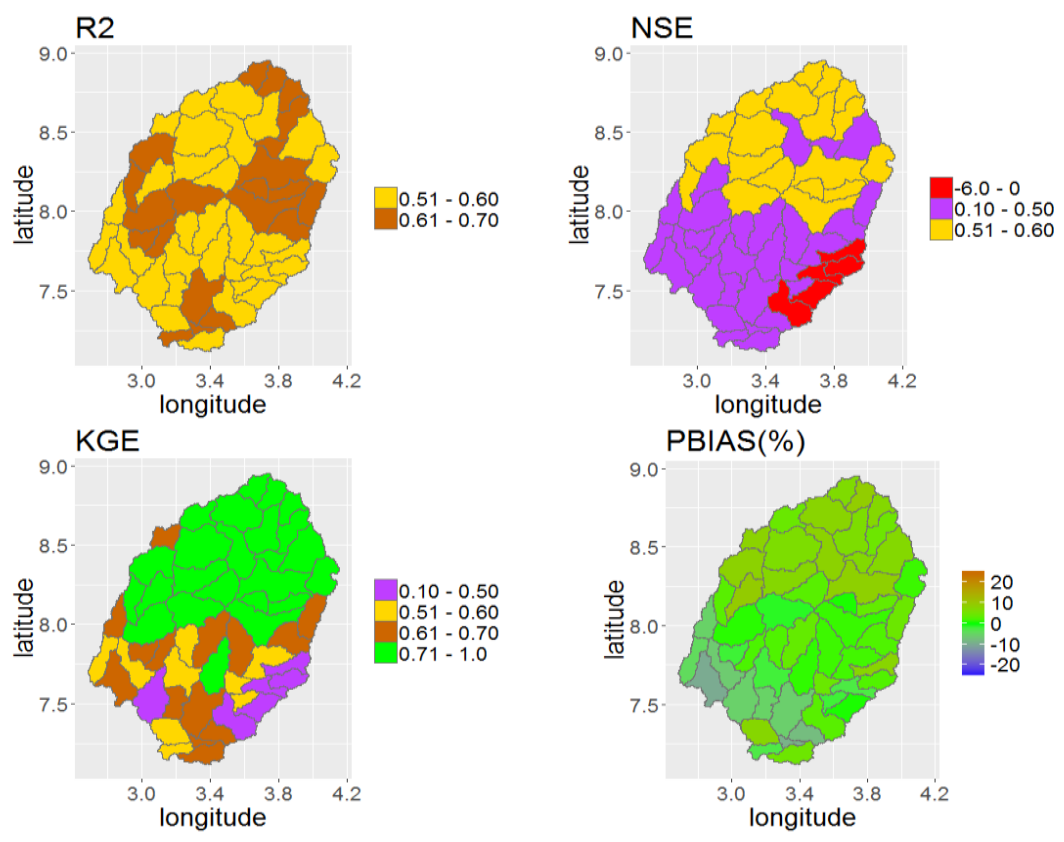

5 Figure S3: Performance metrics (NSE, KGE, $\mathbf{R}^{2}$, and PBIAS) of SWAT (SWAT_P-M) when calibrated with GLEAM_v3.0a (GS3).
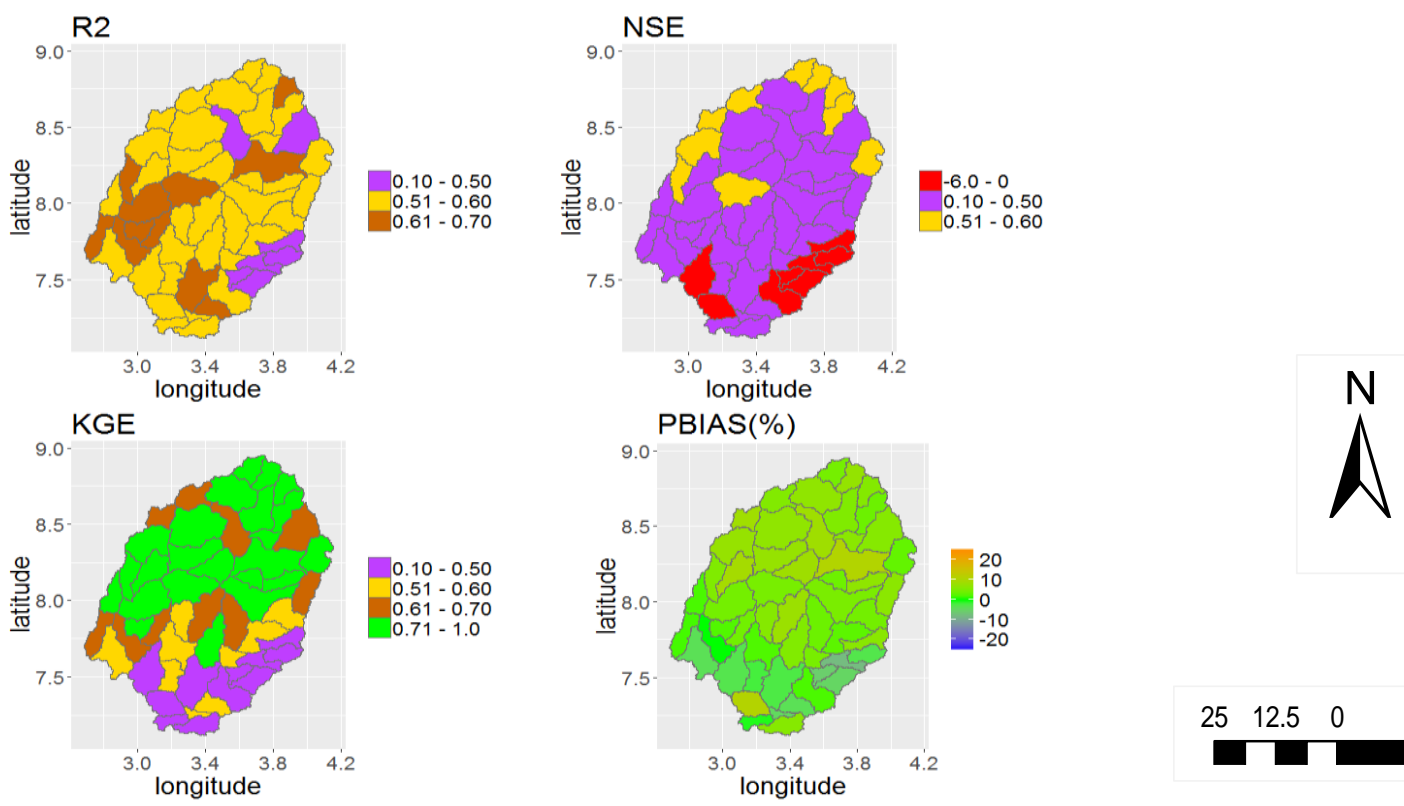

Figure S4: Performance metrics (NSE, KGE, R2, and PBIAS) of SWAT (SWAT_P-M) when validated with GLEAM_v3.0a (GS3). 

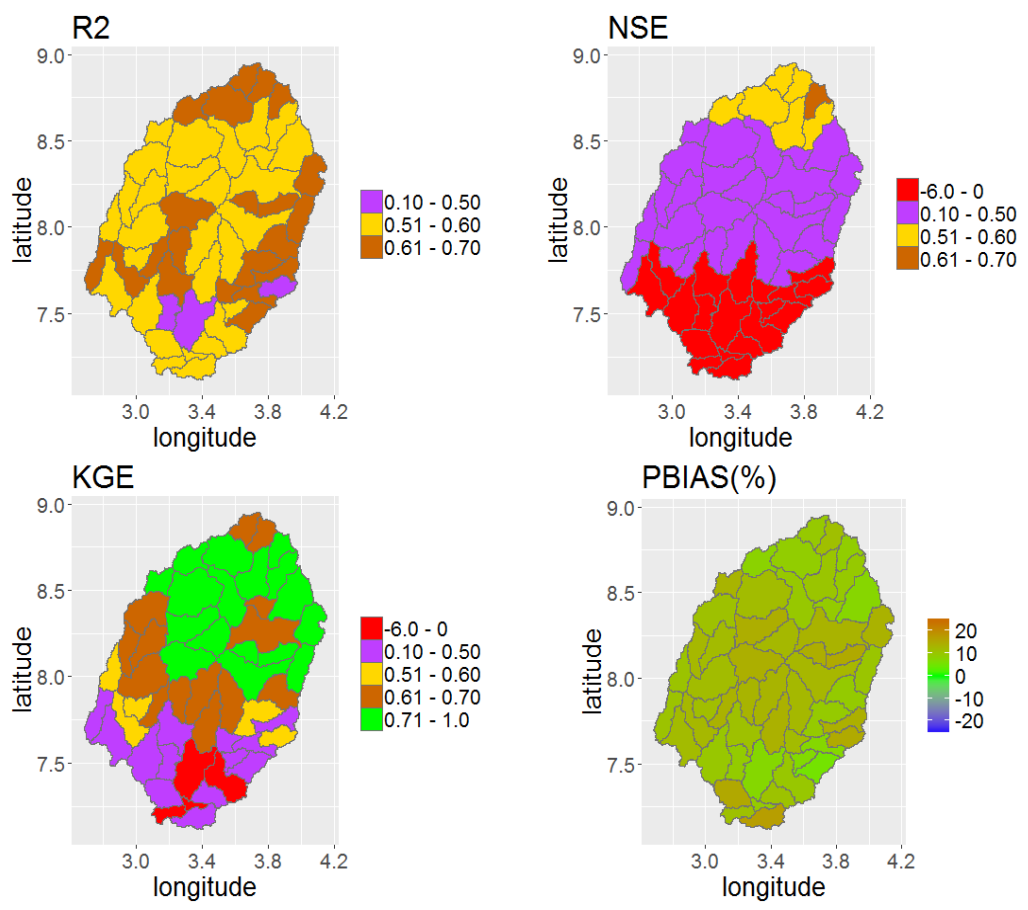

Figure S5: Performance metrics (NSE, KGE, $\mathbf{R}^{2}$, and PBIAS) of SWAT (SWAT_HG) when calibrated with MOD16 (MS4).
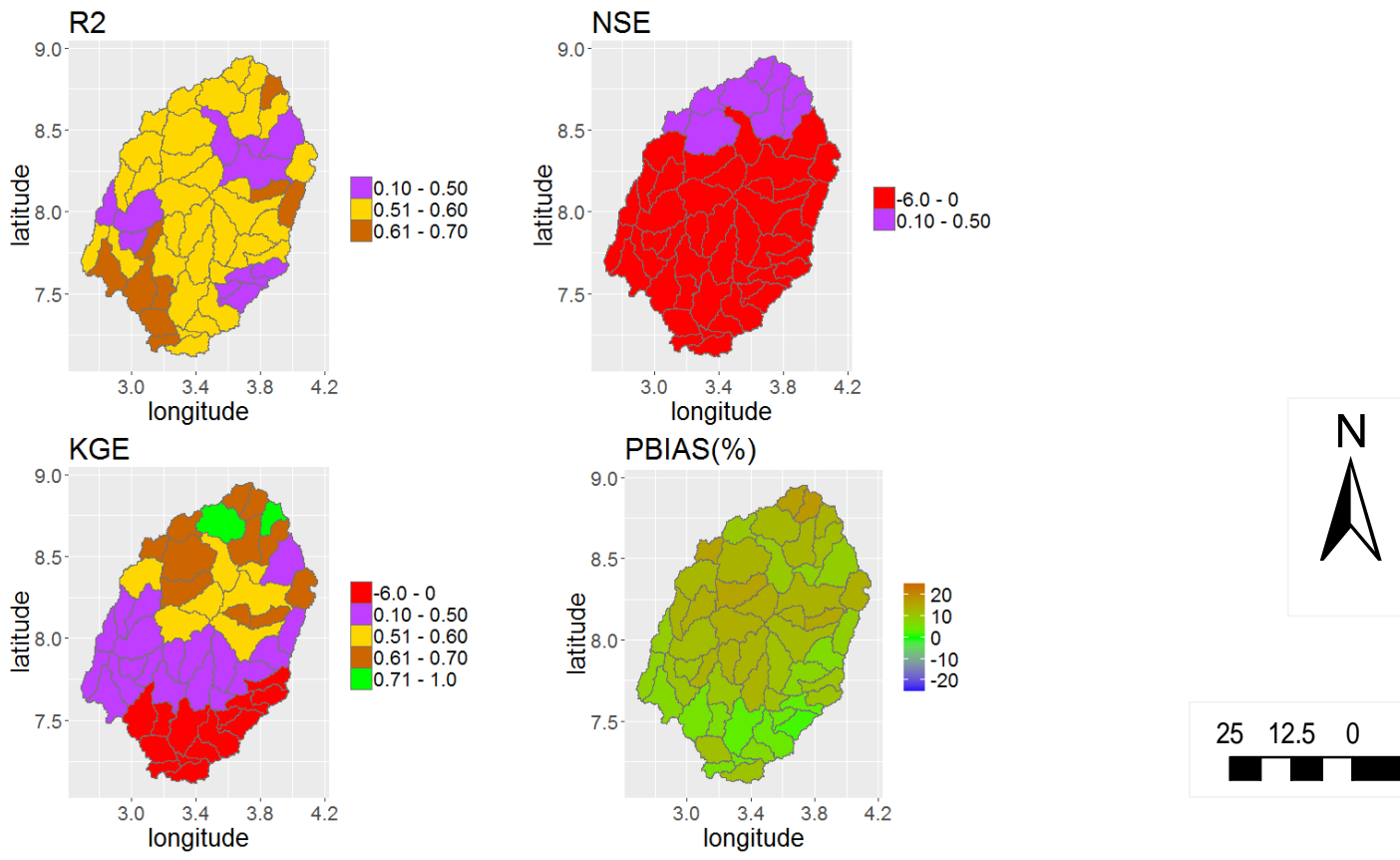

5 Figure S6: Performance metrics (NSE, KGE, $\mathbf{R}^{2}$, and PBIAS) of SWAT (SWAT_HG) when validated with MOD16 (MS4). 

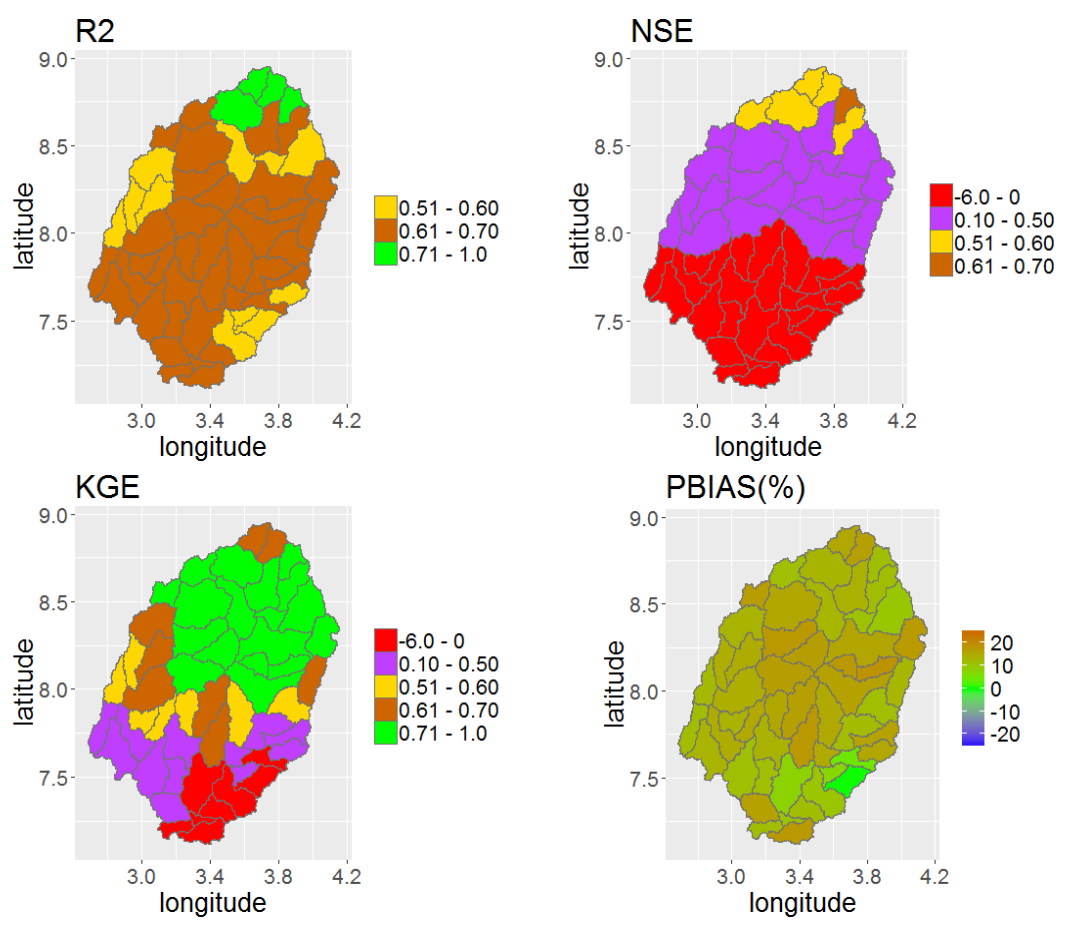

Figure S7: Performance metrics (NSE, KGE, ${ }^{2}$, and PBIAS) of SWAT (SWAT_P-T) when calibrated with MOD16 (MS5).
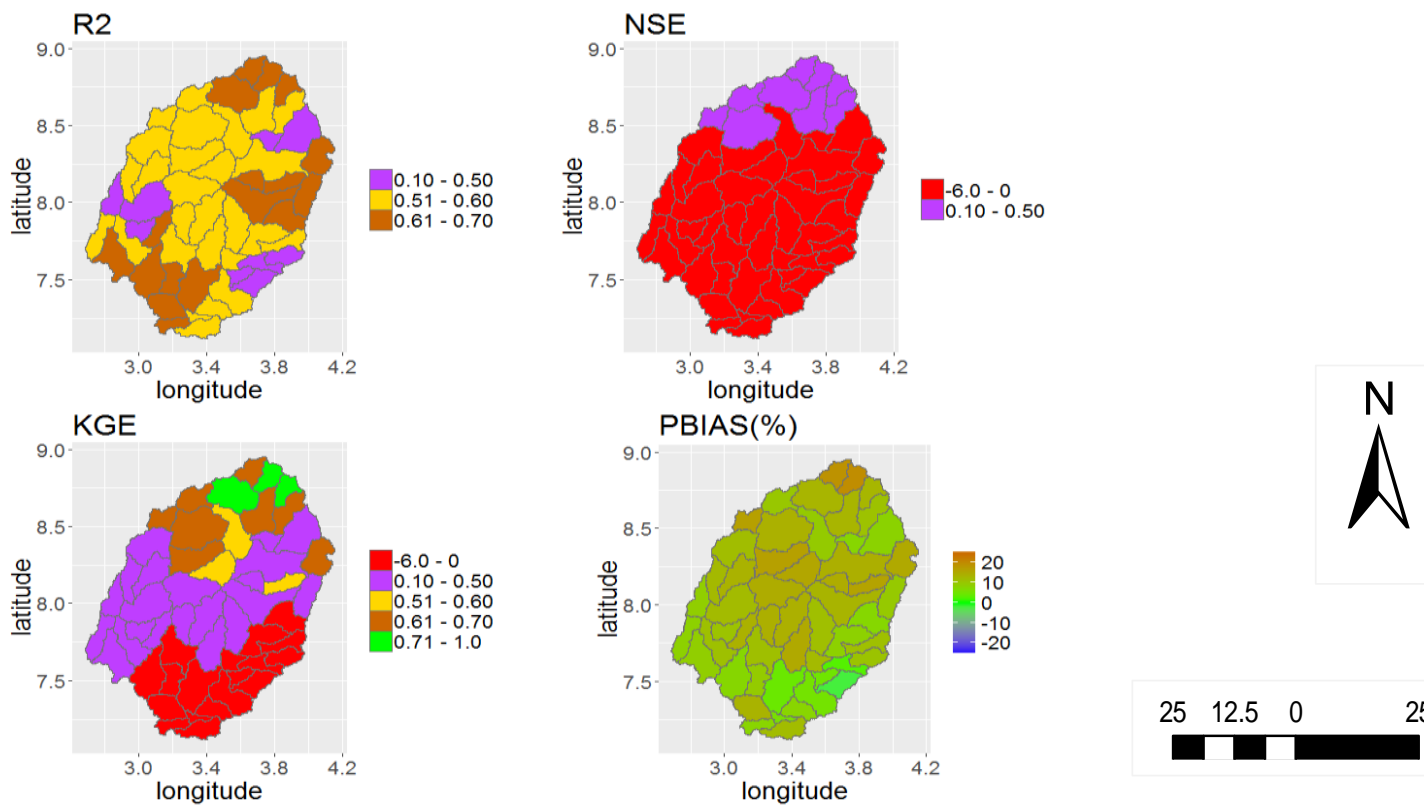

Figure S8: Performance metrics (NSE, KGE, R2, and PBIAS) of SWAT (SWAT_P-T) when validated with MOD16 (MS5). 

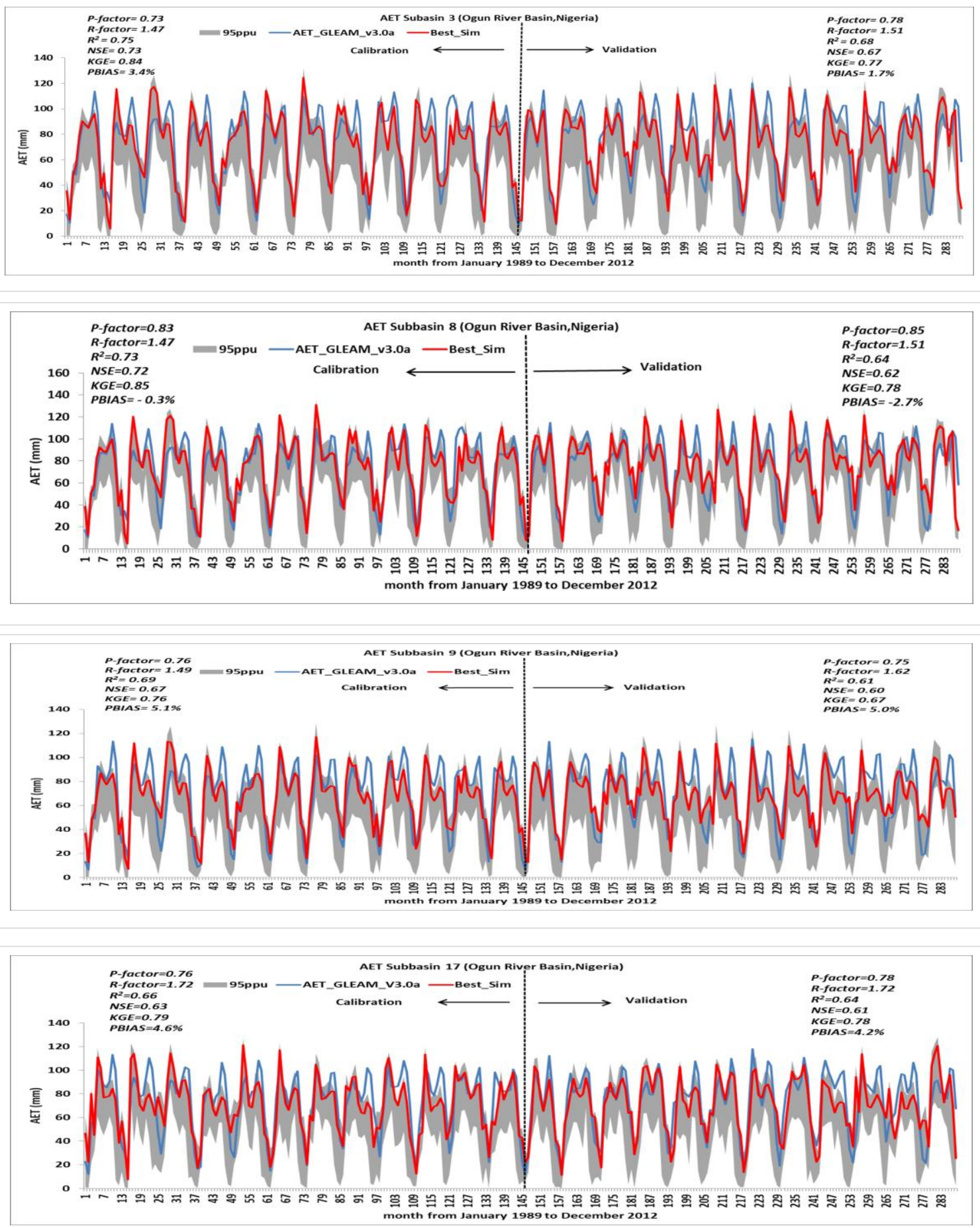

Figure S9: Extracts of the monthly calibration and validation results (GSI) for the selected upstream subbasins (with subbasin 17 where the Ikere gorge dam is located) showing the $95 \%$ prediction uncertainty interval along with the best SWAT simulated actual evapotranspiration and the satellite based actual evapotranspiration (GLEAM-v3.0a). 

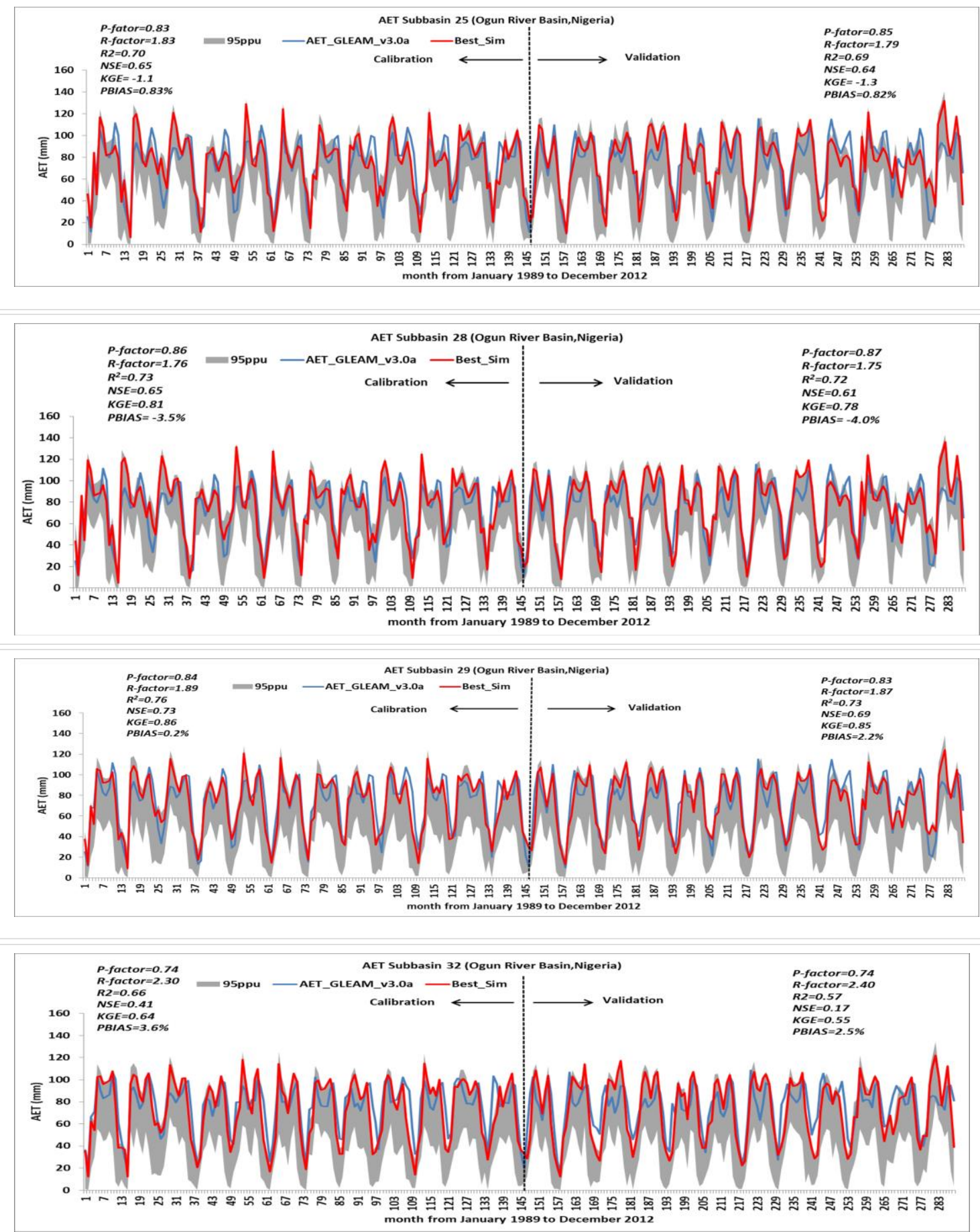

Figure S10: Extracts of the monthly calibration and validation results (GSI) for the selected subbasins (located at the middle of the watershed) showing the $95 \%$ prediction uncertainty interval along with the best SWAT simulated actual evapotranspiration and the satellite based actual evapotranspiration (GLEAM-v3.0a) 


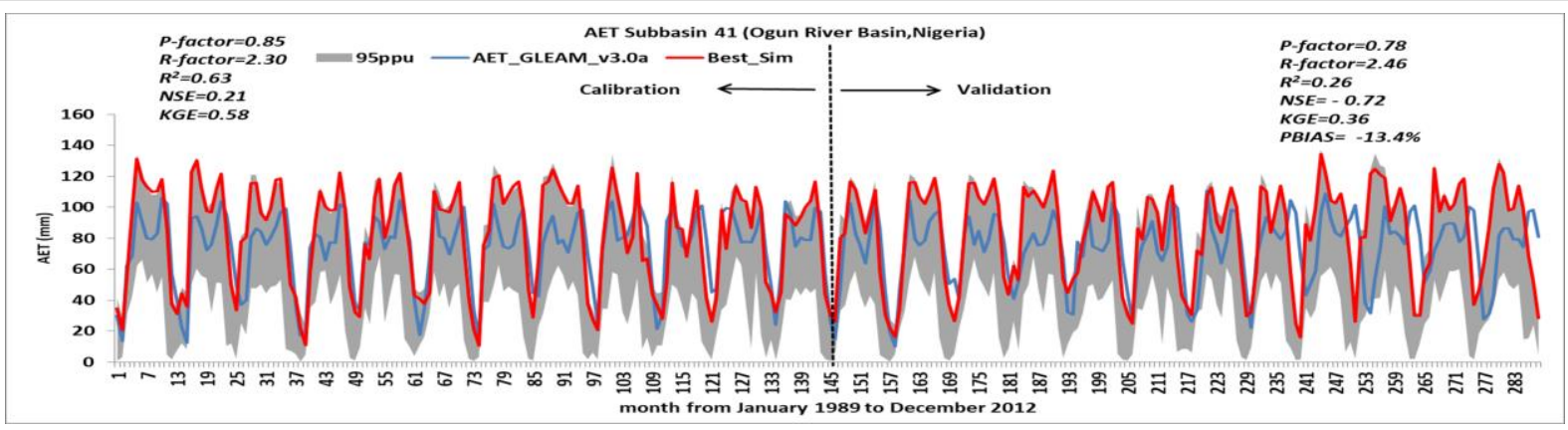

10

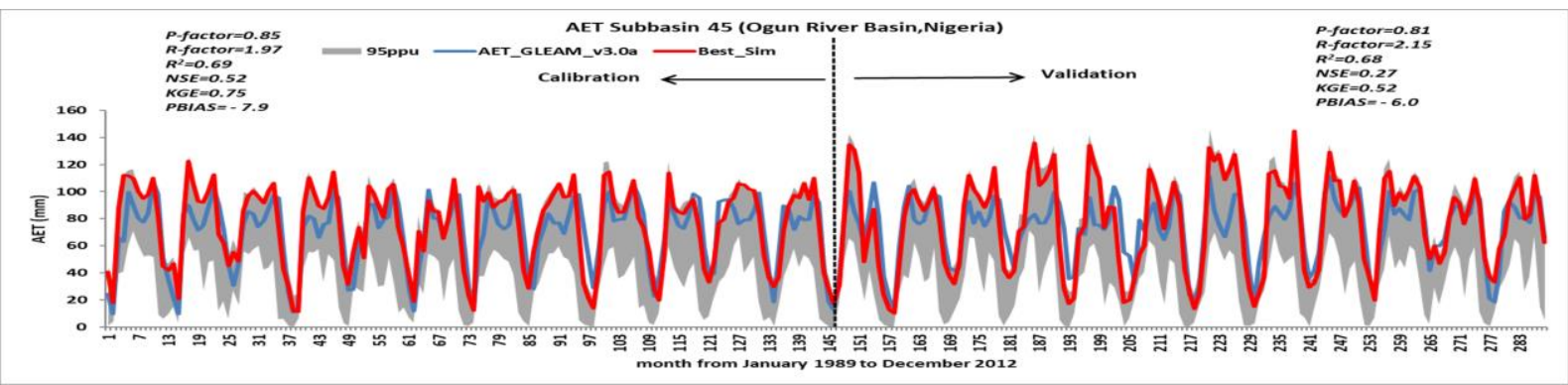

month from January 1989 to December 2012
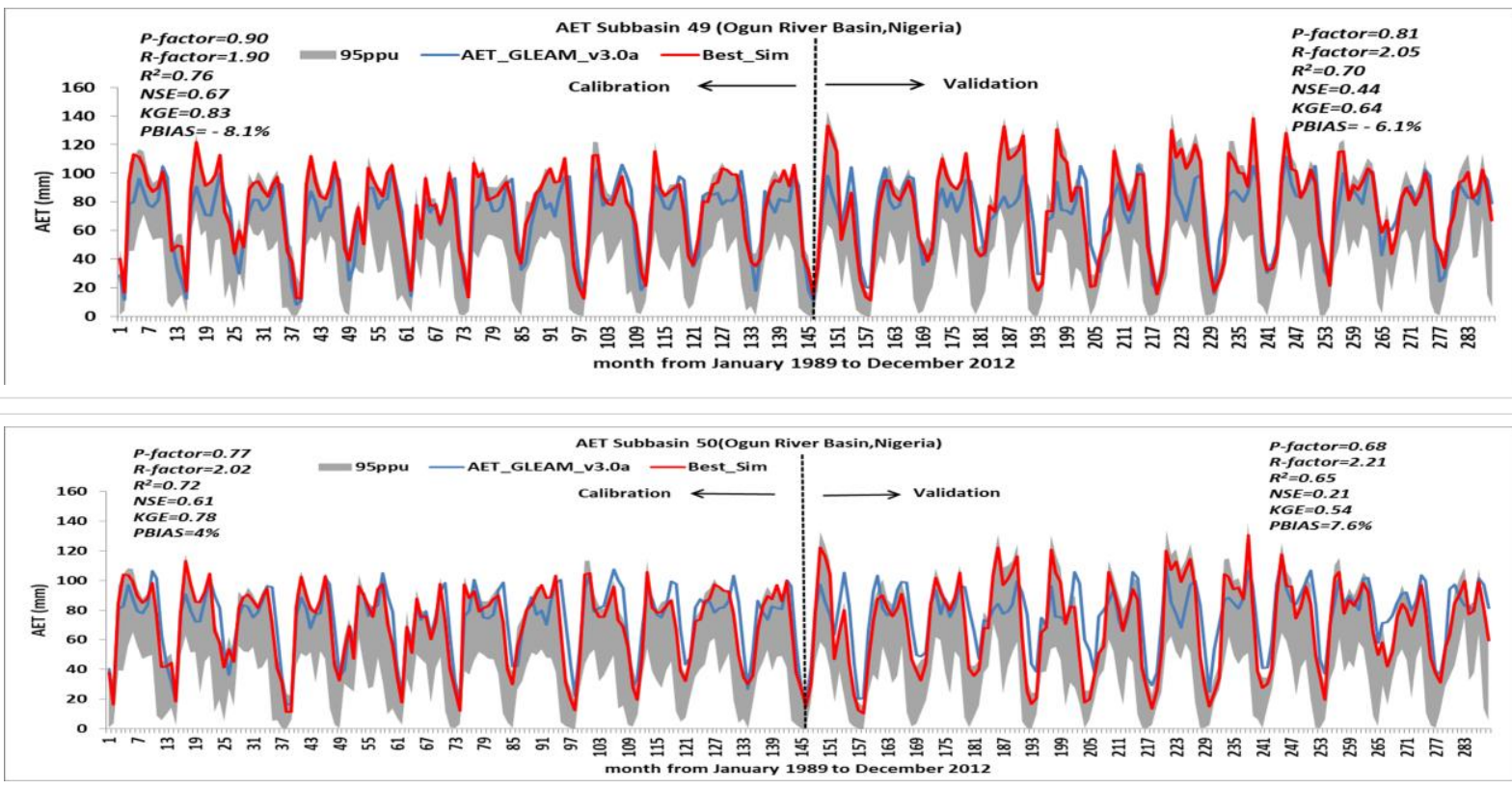

Figure S11: Extracts of the monthly calibration and validation results (GSI) for the selected downstream subbasins (including subbasin 50 where the Oyan dam is located) showing the $95 \%$ prediction uncertainty interval along with the best SWAT simulated actual evapotranspiration and the satellite based actual evapotranspiration (GLEAM-v3.0a). 